\title{
CONSENSUS ON INDICATIONS FOR HEMATOPOIETIC STEM CELL TRANSPLANTATION IN PEDIATRICS. UPDATE 2020: SARCOMAS, EWING FAMILY TUMOR, OSTEOSARCOMA AND HEPATOBLASTOMA
}

Cláudio Galvão de Castro Junior ${ }^{1,2,}$, Paulo Henrique dos Santos Klinger ${ }^{3,4}$, Karoline Helena Silva da Silva ${ }^{5}$, Patrícia Shimoda Ikeuti ${ }^{5}$, Mariana Bohns Michalowski ${ }^{6,7}$, Gabriele Zamperlini Netto MD $^{4,8,9}$, Carla Nolasco Monteiro Breviglieri ${ }^{4,8}$, Fernanda Lima Lelis ${ }^{10.11}$, Natália Maria Tavares Ferreira Borges $^{10,11}$, Simone de Castro Resende Franco ${ }^{12}$, Lauro José Gregianin ${ }^{6,7}$

\author{
1) Instituto Hemomed de Oncologia e Hematologia - São Paulo - SP - Brazil \\ 2) Hospital São Camilo - São Paulo - SP - Brazil \\ 3) Laboratório de Investigação Médica em Patogênese e Terapia dirigida em Onco- \\ Imuno-Hematologia (LIM-31), Departamento de Hematologia, Hospital das Clínicas \\ HCFMUSP, Faculdade de Medicina da Universidade de São Paulo, São Paulo, Brazil \\ 4) Hospital Samaritano - São Paulo - SP-Brazil \\ 5) Instituto de Oncologia Pediátrica - GRAACC - UNIFESP - São Paulo - SP \\ 6) Hospital de Clínicas de Porto Alegre - Porto Alegre - RS - Brazil \\ 7) Departamento de Pediatria - Universidade Federal do Rio Grande do Sul - Porto Alegre - RS - Brazil \\ 8) Instituto do Tratamento do Câncer Infantil ITACI - Hospital das Clínicas - Universidade de São Paulo - São Paulo - SP \\ 9) Hospital Israelita Albert Einstein \\ 10) Hospital Martagão Gesteira - Salvador - BA \\ 11) Hospital São Rafael - Salvador - BA \\ 12) Hospital da Criança de Brasília - Brasília - DF
}

Correspondence to: claudio.junior1967@gmail.com

\begin{abstract}
SUMMARY
The indications for hematopoietic stem cell transplantation in solid tumors in children do not change a lot since our first Brazilian consensus publication in 2009. In this article, we are going to review indications to hematopoietic stem cell transplantation in solid tumors, including the ones that had no more virtual indications.

For the consensus, a review was made using the most relevant articles, and a series of meetings was done to discuss the recommendations.
\end{abstract}

Keywords: Sarcomas, Ewing Sarcoma, Rhabdomyosarcoma; Osteosarcoma; Hepatoblastoma; Hematopoietic Stem Cell Transplantation; Pediatrics

\section{INTRODUCTION}

The indications for hematopoietic stem cell transplantation in solid tumors in children do not change a lot since our first Brazilian consensus publication in $2009^{1}$, In this article, we are going to review indications to hematopoietic stem cell transplantation in solid tumors, including the ones that had no more virtual indications.

For the consensus, a review was made using the most relevant articles, and a series of meetings was done to discuss the recommendations.
Also, there are virtually no studies using allogeneic transplantation, so most of the indication are related to autologous transplantation.

\section{METHODS}

The literature review for the elaboration of this consensus was based on indexed articles, preferably published in the last ten years, including what was published in the annals of national and international congresses. However, considering that many diseas- 
es have few new publications, some diseases have older articles.

Personal experience of the service or of the country, even if not published, can be used to justify indications for transplantation, if the data are properly presented.

\section{RECOMMENDATIONS}

All recommendations are summarized in table one, and more details about each indication is in the following text

\section{EWING FAMILY TUMORS}

There are several studies including a small number of patients suggesting the benefit of using high doses in some subgroups ${ }^{2}$. Patients with relapse might have some benefit from this approach. However, the results of using autologous hematopoietic stem cell transplantation (HSCT) in patients with extrapulmonary metastases have been disappointing ${ }^{3}$.

An article with patients with local and / or distance relapse, found a survival benefit among patients who had a favorable response in multivariate analysis of patients responsive to four to six cycles of conventional relapse chemotherapy shows a better outcome in patients who received additional using autologous hematopoietic stem cell transplantation ${ }^{2}$.

Favorable results were seen in patients with isolated metastatic lung disease in first remission. When there is a good response to conventional initial chemotherapy, these patients seem to benefit from autologous $\mathrm{HSCT}^{4}$.

Also in first remission a study showed that among the 61 patients with a disease considered to be at high risk (metastases, unresectable tumor or poor response to chemotherapy), there was a benefit to those who received consolidation with high doses ( $\mathrm{n}$ $=35$ ) when compared to patients who received only chemo $(n=26)$, with a relapse-free survival of 0.66 vs $0,27(P=0.008)$, respectively 5 .

The Euro-Ewing conducted a randomized study comparing conventional chemotherapy and whole lung irradiation (WLI) versus HCST using Busulfan and melphalan (BuMel). Patients were randomly assigned to VAI plus WLI $(n=143)$ or BuMel $(n=144)$. For overall survival, the Hazard ratio was 1.00 (95\% $\mathrm{Cl}, 0.70$ to $1.44 ; \mathrm{P}=.99)$ The authors do not recommend high doses for this group of patients ${ }^{6}$.

In the other hand, for patients with high-risk localized disease autologous HCST showed a benefit?
Randomization between busulfan and melphalan or standard chemotherapy (vincristine, dactinomycin, and ifosfamide, seven courses) was offered to patients if they were younger than 50 years of age with poor histologic response ( $\geq 10 \%$ viable cells) after receiving vincristine, ifosfamide, doxorubicin, and etoposide (six courses); or had a tumor volume at diagnosis $\geq 200 \mathrm{~mL}$ if unresected, or initially resected, or resected after radiotherapy.

Seventy-eight percent entered the trial because of poor histologic response. In an intent-to-treat analysis, the risk of event was significantly decreased by BuMel compared with VAI: HR, $0.64(\mathrm{P}=.026)$; 8-year EFS were $60.7 \%$ versus $47.1 \%$. Overall survival (OS) also favored BuMel at 8-year OS were $64.5 \%$ versus 55.6\%?

Conditioning using Bu-Mel has been associated with better survival and acceptable toxicity when compared to other regimens and is a recommendation in Ewing Sarcoma Family of tumors ${ }^{6-10}$.

HSCT can be a therapeutic alternative for patients with localized disease and high-risk factors at first remission and should be analyzed on a case-by-case basis in patients with relapse disease. On the other hand, recent the data did not confirm the benefit of high doses for patients with isolated pulmonary metastasis at diagnosis or with metastasis.

\section{OSTEOSARCOMA}

Osteosarcoma, particularly metastatic, still has a limited prognosis. Attempts to intensify treatment with HCST have failed. A study included 71 patients with metastatic or axial osteosarcoma ${ }^{11}$. The patients received one or two cycles of high dose etoposide and carboplatin, the authors conclude that HDCT with carboplatin and etoposide should not be further explored as a treatment strategy in high-risk osteosarcoma.

A review analyzing multiple studies conclude that data regarding HCST in osteosarcoma are inconsistency ${ }^{12}$.

Thus, for patients with osteosarcoma with localized or metastatic disease, there seems to be no significant benefit from transplantation as a rescue therapy.

\section{RHABDOMYOSARCOMA AND NONRHABDOMYOSARCOMA SOFT TISSUE SARCOMAS}

For patients with high-risk or recurrent rhabdomyosarcoma, HCST's superiority over conventional chemotherapy is unclear. 
A old study showed a 3-year event-free survival (EFS) and overall survival (OS) rates were $29.7 \%$ and $40 \%$, respectively, for those receiving high-dose melphalan or other multiagent high-dose regimens and $19.2 \%$ and $27.7 \%$, respectively, for those receiving standard chemotherapy. The difference was not statistically significant $(P=.3$ and $P=.2$ for $E F S$ and $O S$, respectively) ${ }^{13}$.

A more recent study showed a small advantage for patients submitted to HCST, but it was a case series with only 37 patients from 1982 and 2006. The 5-yr EFS for HCST group was $41.3 \% \pm 17.8 \%$ and conventional multi-agent chemotherapy group $16.7 \%$ $\pm 7.6 \%$ for 5 -yr EFS, respectively $(P=0.023)$. In this study there was not a multivariate analysis and to be in a partial or complete remission was also a good prognostic factor ${ }^{14}$.

A retrospective study looking the results in 30 patients showed a three-year OS of $20 \%$ after allogeneic transplantation for relapsed or refractory rhabdomyosarcoma. Cumulative risk of progression was $67 \%$. Eighteen patients died of disease and four of complications. Eight patients survived in complete remission (CR) (median: 44 months). No patients with residual disease before allo-SCT were converted to $\mathrm{CR}^{15}$.

Data for other soft tissue sarcomas are scarse ${ }^{16}$, published mainly more than 10 years ago and limited to case series.
There were no recent reports about transplantation in sarcomas and systematic reviews of rhabdomyosarcoma ${ }^{17}$ or nonrhabdomyosarcoma soft tissue sarcoma ${ }^{18}$ showed no benefit in using this approach.

For this diseases HCST should be considered only in case by case analysis or in clinical trials.

\section{HEPATOBLASTOMA}

Hepatoblastoma particularly those who relapse and those with metastases at diagnosis. Hepatoblastoma is also an uncommon pediatric cancer and all case series are small.

Anecdotic case reports showed a potential benefit for autologous transplantation, but more extensive reviews were not able to have any definitive conclusion ${ }^{19,20}$.

The German HB99 trial (1999-2008) for hepatoblastoma $(\mathrm{HB})$, was primarily to analyse the effect of high dose (HD) chemotherapy with carboplatin/etoposide (CE) in high risk (HR), Use of HD chemotherapy for HB did not improve patient outcomes, compared to contemporaneous and more recent trials like SIOPEL $4{ }^{21}$.

Some reviews also showed that HSCT does not appear to be superior to the multimodal therapy currently used ${ }^{22}$.

Hepatoblastoma is not a currently indication for HCST and this approach may only used in clinical trials or after case by case discussions.

TABLE 1- Indications for Hematopoietic Stem cell Transplantation in Pediatric Solid Tumors

\begin{tabular}{c|c|c}
\hline \multicolumn{1}{c|}{ Tumor } & Autologous & Allogeneic \\
\hline Ewing Sarcoma - First line High risk features & $\mathrm{Cl}$ & $\mathrm{NR}$ \\
\hline Ewing Sarcoma - Relapse & $\mathrm{Cl}$ & $\mathrm{NR}$ \\
\hline Osteosarcoma & $\mathrm{NR}$ & $\mathrm{NR}$ \\
\hline Nonrhabdomyosarcoma soft tissue sarcoma & $\mathrm{NR}$ & $\mathrm{NR}$ \\
\hline Rhabdomyosarcoma & $\mathrm{NR}$ & $\mathrm{NR}$ \\
\hline Hepatoblastoma & NR \\
\hline
\end{tabular}

Legend: Clinically indicated (Cl) Clinical option (OC) - Generally not recommended (NR) 


\section{REFERENCES}

1. Seber A, Bonfim CMS, Daudt LE, et al . Indicações de transplante de células-tronco hematopoéticas em pediatria: consenso apresentado no I Encontro de Diretrizes Brasileiras em Transplante de Células-Tronco Hematopoéticas - Sociedade Brasileira de Transplante de Medula Óssea, Rio de Janeiro, 2009. [Indications for pediatric hematopoietic stem cell transplantation: consensus presented at the First Meeting on Brazilian Hematopoietic Stem Cell Transplantation Guidelines - Brazilian Society of Bone Marrow Transplantation, Rio de Janeiro, 2009]. Rev Bras Hematol Hemoter. 2010;32(3):225-239

2. Rasper $M$, Jabar $S$, Ranft $A$, Jürgens $H$, et al. The value of high-dose chemotherapy in patients with first relapsed Ewing sarcoma. Pediatr Blood Cancer. 2014;61(8):1382-6

3. Rodriguez-Galindo C, Spunt SL, Pappo AS. Treatment of Ewing sarcoma family of tumors: current status and outlook for the future. Med Pediatr Oncol. 2003;40(5):276-87

4. Oberlin O, Rey A, Desfachelles AS, et al. Impact of high-dose busulfan plus melphalan as consolidation in metastatic Ewing tumors: a study by the Société Française des Cancers de Enfant. J Clin Oncol. 2006;24(24):3997

5. Drabko K, Raciborska A, Bilska K, et al. Consolidation of first-line therapy with busulphan and melphalan, and autologous stem cell rescue in children with Ewing\&\#39;s sarcoma. Bone Marrow Transplant. 2012;47(12):1530-4

6. Dirksen U, Brennan B, Le Deley MC et al. HighDose Chemotherapy Compared With Standard Chemotherapy and Lung Radiation in Ewing Sarcoma With Pulmonary Metastases: Results of the European Ewing Tumour Working Initiative of National Groups, 99 and EWING 2008. J Clin Oncol. 2019;37(34):3129-3202.

7. Whelan J, Le Deley MC, Dirksen U, et al. HighDose Chemotherapy and Blood Autologous Stem-Cell Rescue Compared With Standard Chemotherapy in Localized High-Risk Ewing Sarcoma: Results of Euro-E.W.I.N.G.99 and Ewing-2008. J Clin Oncol. 2018;36(31): JCO2018782516.

8. Ladenstein R, Pötschger U, Le Deley MC, et al. Primary disseminated multifocal Ewing sarcoma: results of the Euro-EWING 99 trial. J Clin On- col 28:3284-91, 2010

9. Diaz MA, Lassaletta A, Perez A, Sevilla J, Madero $L$, Gonzalez-Vicent M. High-dose busulfan and melphalan as conditioning regimen for autologous peripheral blood progenitor cell transplantation in high-risk ewing sarcoma patients: a long-term follow-up single-center study. Pediatr Hematol Oncol. 2010;27(4):272-82

10. Ferrari S, Sundby Hall K, Luksch R, et al. Nonmetastatic Ewing family tumors: high-dose chemotherapy with stem cell rescue in poor responder patients. Results of the Italian Sarcoma Group/ Scandinavian Sarcoma Group III protocol. Ann Oncol 2011;22:1221-7.

11. Karadurmus N, Sahin U, Bahadir Basgoz B, et al. Is there a role of high dose chemotherapy and autologous stem cell transplantation in the treatment of Ewing's sarcoma and osteosarcomas? J BUON. 2018;23(5):1235-1241

12. Boye K, Del Prever AB, Eriksson M, et al. HighDose Chemotherapy with Stem Cell Rescue in the Primary Treatment of Metastatic and Pelvic Osteosarcoma: Final Results of the ISG/SSG II Study. Pediatr Blood Cancer. 2014;61:840-845.

13. Carli M, Colombatti R, Oberlin O, et al. Highdose melphalan with autologous stem-cell rescue in metastatic rhabdomyosarcoma. J Clin Oncol. 1999;17(9):2796-803

14. Kim NK, Kim HS, Suh CO, et al. Clinical Results of High-Dose Chemotherapy Followed by Autologous Peripheral Blood Stem Cell Transplantation in Children with Advanced Stage Rhabdomyosarcoma. J Korean Med Sci. 2012;27:1066-1072.

15. Thiel U, Koscielniak E, Blaeschke F, et al. Allogeneic stem cell transplantation for patients with advanced rhabdomyosarcoma: a retrospective assessment. Br J Cancer. 2013;109(10):2523-32.

16. Blay JY, Bouhour D, Ray-Coquard I, et al. Highdose chemotherapy with autologous hematopoietic stem-cell transplantation for advanced soft tissue sarcoma in adults. J Clin Oncol. 2000;18(21):3643-50.

17. Peinemann F, Kröger N, Bartel C, et al. Highdose chemotherapy followed by autologous stem cell transplantation for metastatic rhabdomyosarcoma--a systematic review. PLoS One. 2011;6(2):e17127 
18. Peinemann F, Enk H, Smith LA. Autologous hematopoietic stem cell transplantation following high-dose chemotherapy for nonrhabdomyosarcoma soft tissue sarcomas. Cochrane Database Syst Rev. 2017;4(4):CD008216

19. Niwa Umeda K, Awaya T, et al. Successful autologous peripheral blood stem cell transplantation with a double-conditioning regimen for recurrent hepatoblastoma after liver transplantation. Pediatr Transplant. 2009;13(2):259-62.

20. Provenzi M, Saettini F, Conter V, et al. Is there a role for high dose chemotherapy and blood stem cell rescue in childhood hepatoblastoma presenting with lung metastases? A case report and literature review. Ital J Pediatr. 2013;39:65.

21. Häberle B, Maxwell R, Schweinitz DV, Schmid I. High Dose Chemotherapy with Autologous Stem Cell Transplantation in Hepatoblastoma does not Improve Outcome. Results of the GPOH Study HB99. Klin Padiatr. 2019;231(6):283-90.

22. Karski EE, Dvorak CC, Leung W, et al. Treatment of hepatoblastoma with high-dose chemotherapy and stem cell rescue: the pediatric blood and marrow transplant consortium experience and review of the literature. J Pediatr Hematol Oncol. 2014;36(5):362-8 